ACTA UIVERSITATIS CIBINIENSIS - TECHNICAL SERIES

Vol. LXV 2014

\title{
KNOWLEDGE MANAGEMENT PLATFORM IN ADVANCED PRODUCT QUALITY PLANNING
}

\author{
Bogdan CHILIBAN \\ Faculty of Engineering, "Lucian Blaga" University, Sibiu, Romania, bogdan.chiliban@gmail.com
}

Lal Mohan BARAL

Faculty of Engineering, "Lucian Blaga" University, Sibiu, Romania, Ialmohan_baral@yahoo.com

Claudiu KIFOR

Faculty of Engineering, "Lucian Blaga" University, Sibiu, Romania, claudiu.kifor@ulbsibiu.ro

\begin{abstract}
Knowledge is an essential part of organizational competitiveness. This vital resource must be managed correctly within organizations in order to achieve desired performance levels within all undertakings. The process of managing knowledge is a very difficult one due to the illusive nature of the resource itself. Knowledge is stored within every aspect of an organization starting from people and ending with documents and processes. The Knowledge Management Platform is designed as a facilitator for managers and employees in all endeavours knowledge related within the Advanced Product Quality Planning Procedure.
\end{abstract}

Key words: APQP, Knowledge, Knowledge Management, Knowledge Management Platform

\section{Introduction}

Within this paper a high level overview of a Knowledge Management tool will be presented. The main region of instantiation, that has been at the basis of the development of such a tool, is the Advanced Product Quality Planning, a procedure mainly utilized in the automotive industry (Ford/GM/Chrysler, 1995). Although this particular Knowledge Management Platform has been developed with the automotive industry in mind it could be altered to fit other industries. This is because the quality planning process within the APQP can be applicable in all industries (Borbek \& Sokovic, 2005), (Morris, 2012)

The APQP procedure has been developed by the American "big three" car companies as a direct response to the competitive pressure asserted on them by the Asian players on the market. It is a standardized procedure to be applied along the entire supply chain of the organization, within each and every product and process development procedure.

The APQP procedure is characterized by an intensive need for highly specialized and connected, dependent, knowledge across all its activities. This means that knowledge and especially knowledge management activities become crucial to the development of a successful product and process. For this reason the KMP tool is attempting to become a holistic approach to knowledge management instantiations. 
Figure 1: APQP procedure (Ford/GM/Chrysler, 1995)

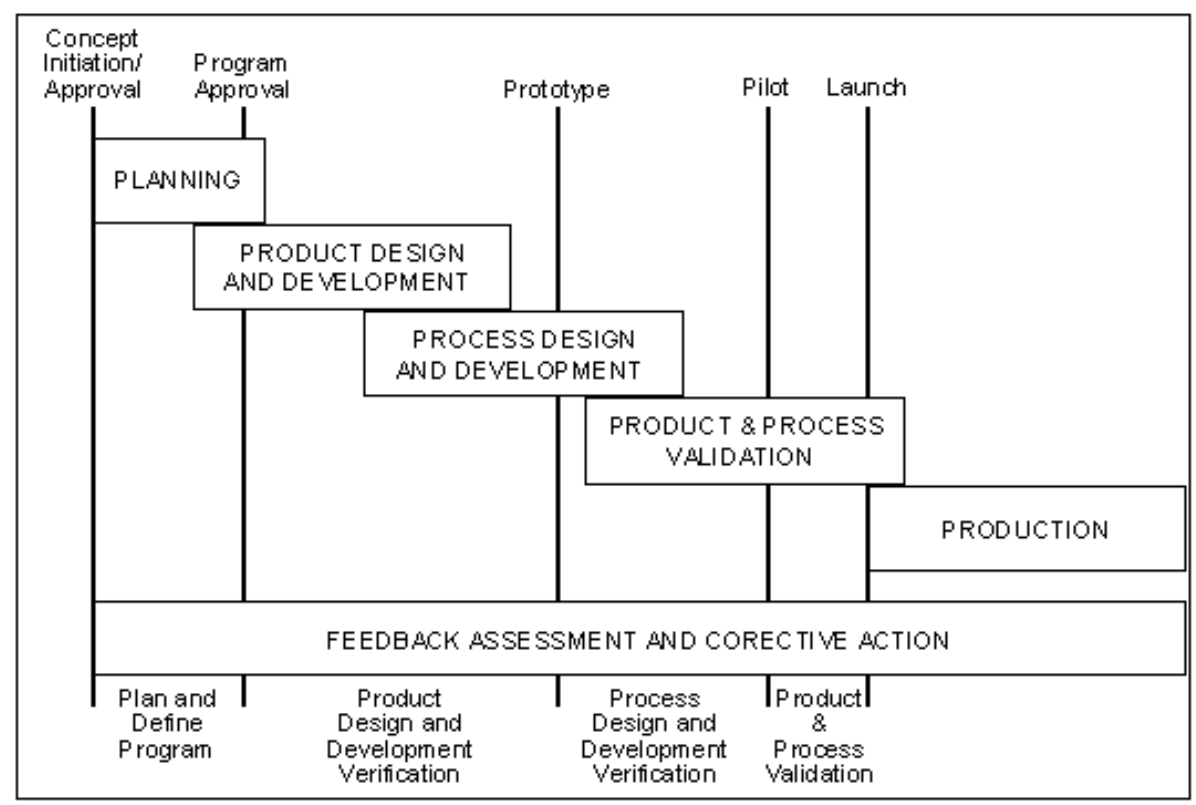

\section{Knowledge and Knowledge Management}

Knowledge has been defined by the Greek philosopher Plato in his work Thaetaus as "Justified true belief". Although this definition has been proposed thousands of years ago to this day a reconciling view of what knowledge truly is has not been achieved. This is due to the ambiguity of the notion.

The Oxford dictionary defines knowledge as " facts, information, and skills acquired by a person through experience or education; the theoretical or practical understanding of a subject" (Oxford Dictionary).

There are many other definitions available for the concept that vary not only from author to author but also from field of study to field of study. In this continuing debate two main sides have risen. The first suggests that knowledge can exist only in the human mind and as a result cannot be externalized. Any externalization of knowledge is in their view a transformation of said knowledge into information and nothing more (Wilson, 2002), (Galliers \& Newell, 2003). The second view which is also the prevailing one considers that knowledge can exist outside of the human mind and can be hosed in documents processes, products etc (Davenport, Long, \& Beers, 1998) (Nonaka \& Takeguci, 1995) (Polanyi, 1967) (King, 2005). This notion directly implies that knowledge is a commodity that can be traded developed outside of a single individuals mind and as the case may be even stolen. This view has its starting point in Michael Polanyi (1967) who first suggested that there are two different types of knowledge: explicit knowledge and tacit knowledge. Explicit knowledge is easily codified, understandable and transferable between individuals. Tacit knowledge on the other hand is impossible to codify, is highly dependent and very difficult to transfer between individuals. This represents the knowledge that is at the heart of any successful APQP procedure and as a direct result this is why managing knowledge is vital to an organizations success.

As is the case in any emerging field of study a universal definition for the concept of knowledge management does not exist at the present time. Below are presented a few examples of definitions

Knowledge Management is the process of acquiring knowledge from the organization or another source and turning it into explicit information that the employees can use to transform into their own knowledge allowing them to create and increase organizational knowledge (Kiku \& Lori, 2009).

Knowledge Management is the planning, organizing, motivating, and controlling of people, processes and systems in the organization to ensure that its knowledge-related assets are improved and effectively employed (King W. R., 2009).

Knowledge Management is a process of creating, acquiring, capturing, aggregating, sharing, and using knowledge, wherever it resides, to enhance organizational learning and performance (BeccaFernandez \& Leidner, 2008) (Boomer, 2004).

Knowledge Management is a systemic effort to enable information and knowledge to grow, flow and create value (O'Dell \& Hubert, The New Edge in Knowledge, 2011). 
From these definitions a conclusion can be drawn. KM is a continuous process that involves various predefined steps whose main goal is the well being of the organization thru increased performance in all aspects. The importance of knowledge management cannot be overestimated in the business filed. Lew Platt, former CEO of Hewlett Packard. He stated "If only HP knew what it knows it would make three times more profit tomorrow".

Knowledge Management involves the management of the relationship between tacit-the knowhow possessed by individuals-and explicit knowledge-the systemically documented know-how that becomes available to everyone in the organization (Ruggles, 1999). The ultimate goal of knowledge management should be to convert tacit knowledge to explicit knowledge to transform the capacity of individuals within the organization to use information strategically and apply higher-order thinking to an informed decision- making process.

\section{Knowledge Management Platform}

The Knowledge Management Platform (KMP) is designed with the goal of facilitating the KM process by encouraging knowledge generation and shearing. The platform is an online tool that can be accessed by all members of the organization. It is divided into six main components: Hierarchy, APQP, Q and A, Education, Extracurricular Activities and Recommendations. Its goal is to create an organizational wide Knowledge and Connections hierarchy for the knowledge managers and to be a repository for all elements linked to the KM process.

\section{Figure 2: Knowledge Management Platform}

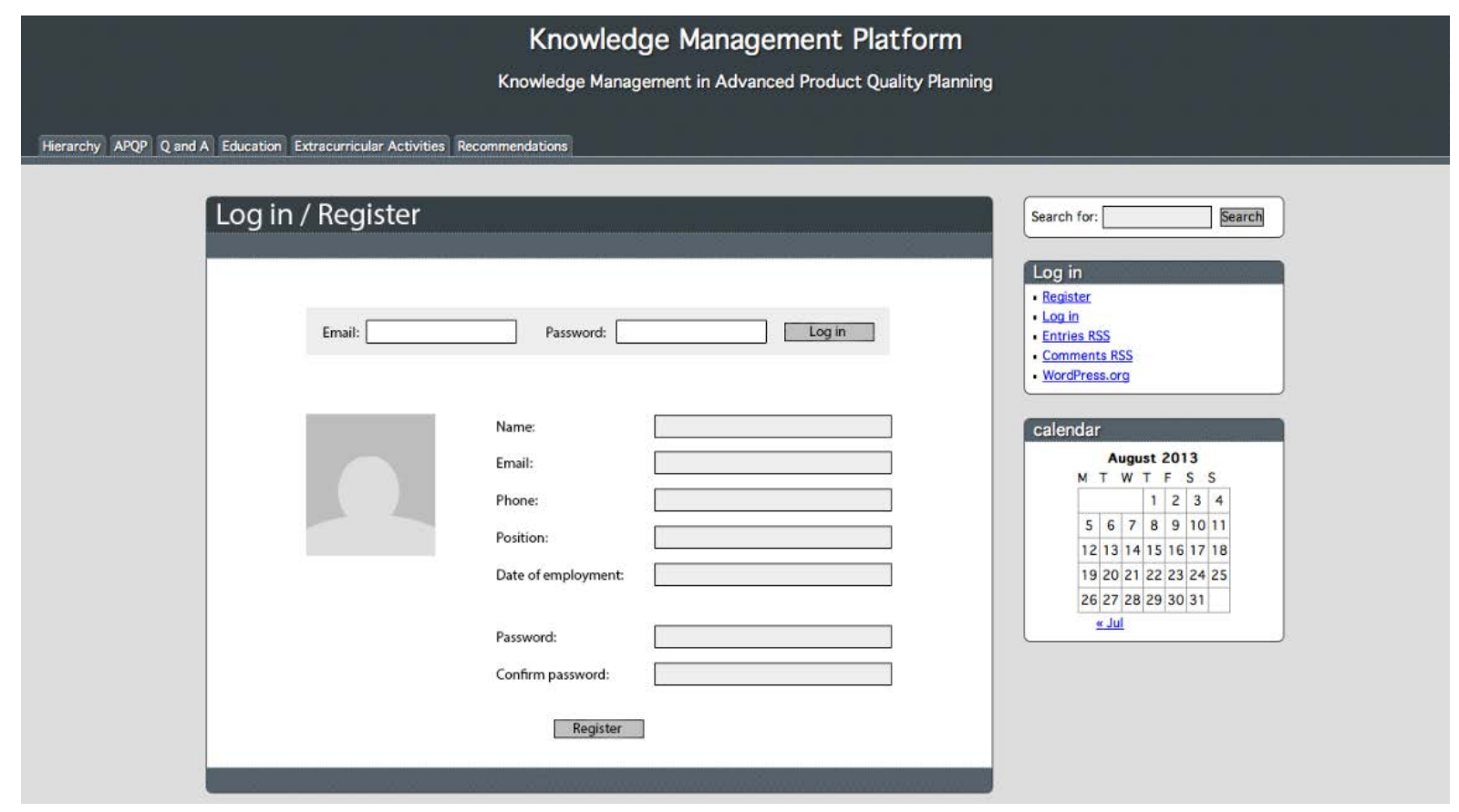

Within the Hierarchy tab two main elements will be present: the Knowledge Hierarchy (Figure 2) and the Connections Map (Figure 3).

The Knowledge Hierarchy will be an organizational wide tool, with the goal of calculating and displaying in a transparent manner each individuals Knowledge Levels. These will be calculated based on various formulas that will not be presented within the confines of this paper but which are linked to the aforementioned tabs of the platform: APQP, Q and A, Education, Extracurricular Activities and Recommendations.

The KH will show for a certain specialization (e.g. quality engineers) the levels of knowledge for all members of an organization. These levels are: Distinguished Expert, Expert, Master, Practitioner, Initiate, Honour Student, Student. Based on these levels managers can allocate the human resource at their disposal in a more efficient and effective manner. It is of vital importance that the KH be linked to an appropriate reward system that will represent the extrinsic motivator for employees to devote time and effort into the adequate development and utilization of this Knowledge Tool. 
Figure 3: KMP Knowledge Hierarchy

\section{Hierarchy / Knowledge}

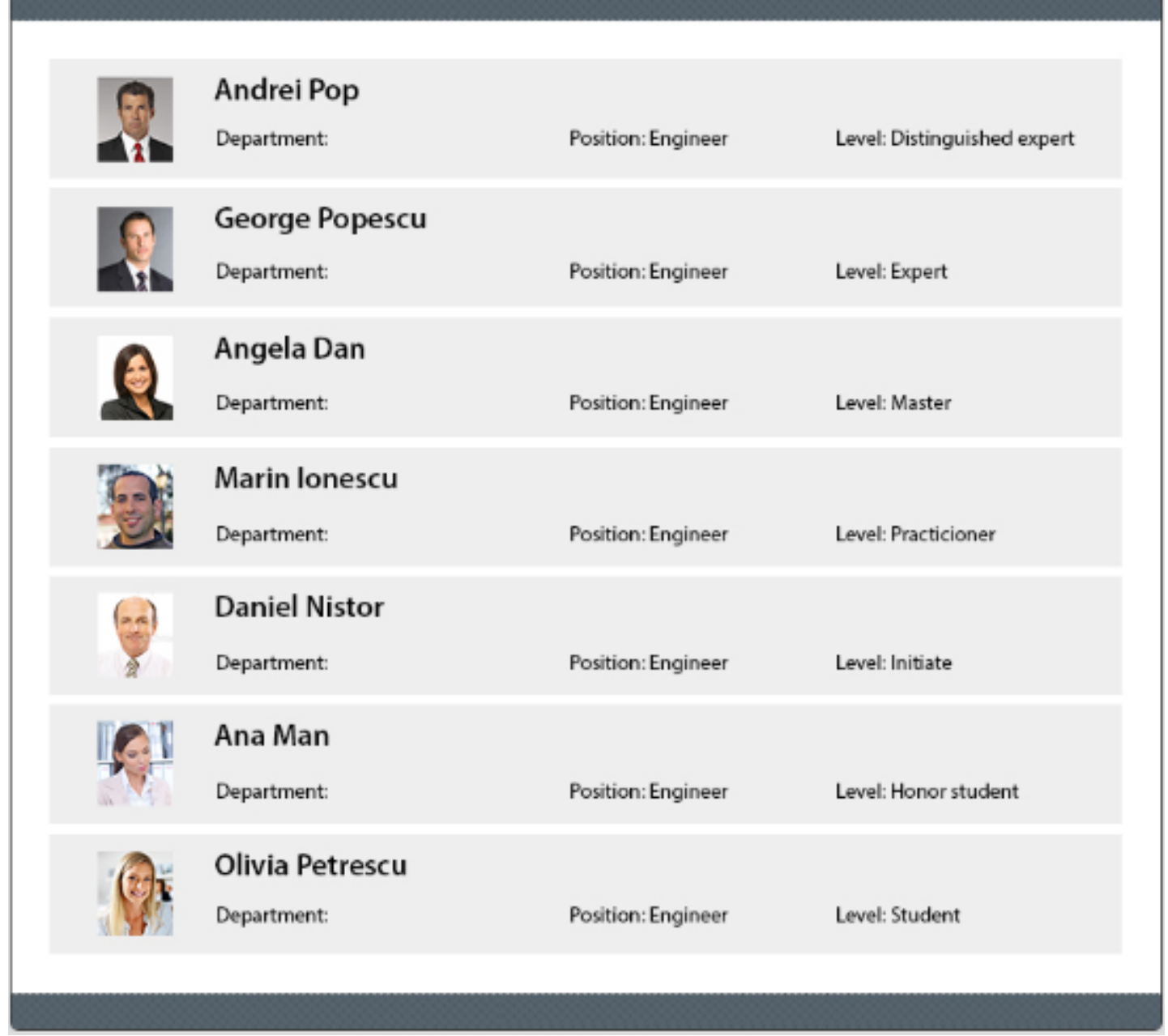

The Connections Map presented below is important because it presents in an easily understandable manner the amount of connections existent between various members of the organization. Utilizing this tool managers can easily ascertain which individuals interact the most inside the organization and based on their involvement in various APQP procedures can identify not only the most knowledgeable people at their disposal but also the best possible teams and parings of said individuals.

In the figure below the map is presented. Each balloon represents a member of the organization, their colours represent the various departments that make up the company. By clicking any of them, the tool will generate an image in which the persons with whom that individual has the most interactions in the company is displayed as an enlarged element, the size being directly proportionate to the number of connections between the two. 


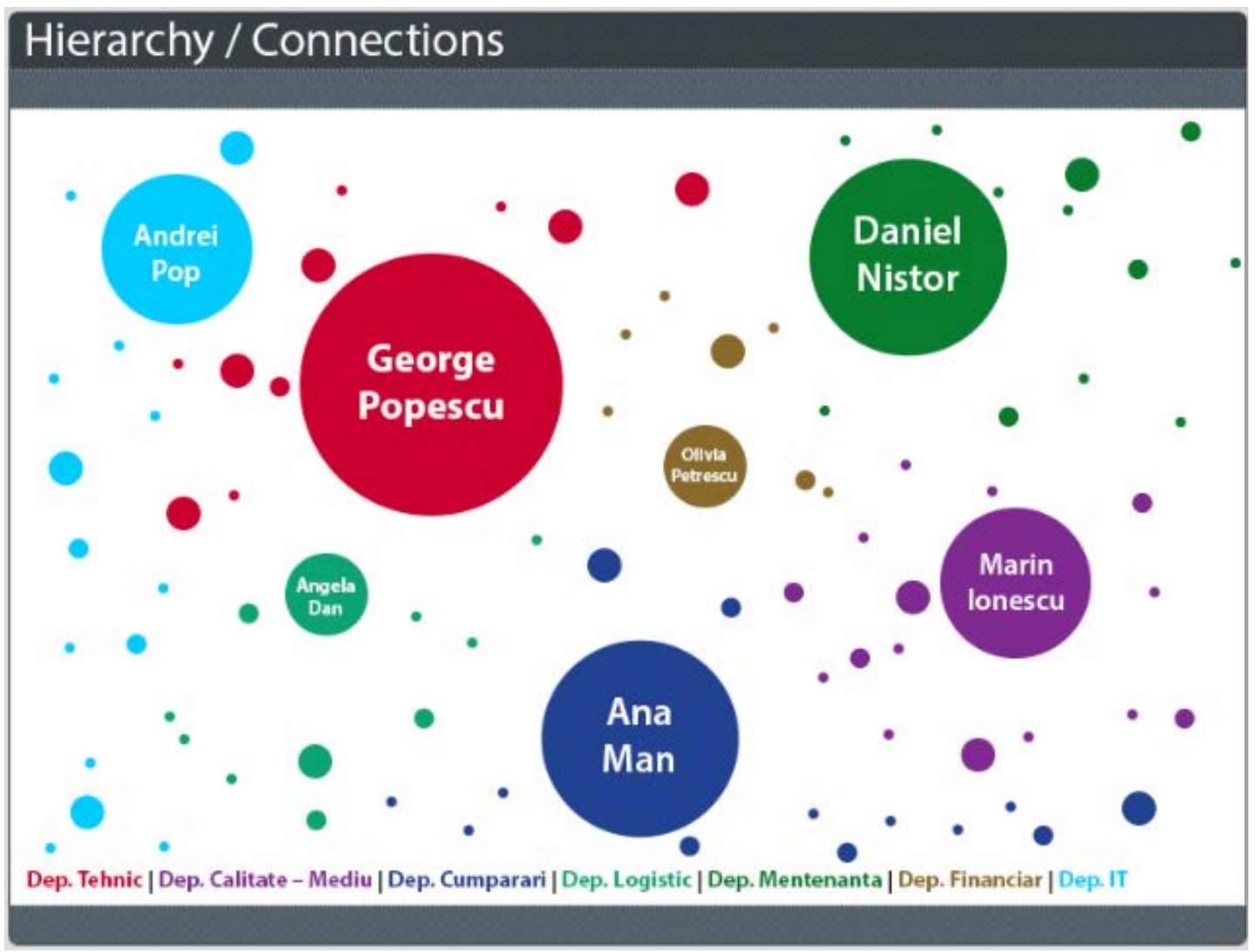

\section{Conclusions}

The APQP procedure is a knowledge intensive undertaking that requires vast amounts of tacit and explicit knowledge to be correctly utilized in order to obtain a competitive advantage for the organization. Because tacit knowledge is dependent, impossible to codify and difficult to transfer the KMP facilitates and actively encourages communication and interaction between members of the organization in an attempt to enable externalization of said knowledge. Also the APQP, Q and A and Recommendations tabs act as a easily accessible and searchable repository of explicit knowledge.

By consistently utilizing and updating the content of the KMP improvements in product and process quality, time to markets, profitability can be achieved. This tool will prevent opacity along organizational boundaries, knowledge hoarding and promote a more open and collaborative environment.

As a final statement that cements the paramount importance of knowledge and knowledge management Nonaka and Takeguci affirm: "In an economy where the only certainty is uncertainty, the one sure source of lasting competitive advantage is knowledge" (Nonaka \& Takeguci, 1995)

\section{References}

- Becca-Fernandez, I., \& Leidner, D. (2008). Individual, group, and organizational learn- ing: A knowledge management perspective. In I. Becca-Fernandez, \& D. Leidner, Knowledge Management: An Evolutionary View (pp. 13-39). New York: M. E. Sharpe.

- Boomer, J. (2004). Finding out what knowledge management is-and isn't. Accounting Today, 18(14) , 9-22.

- Borbek, M., \& Sokovic, M. (2005). Implementation of APQP - concept design of QMS. Journal of Materials Processing Technology , 718-724.

- Davenport, T. H., Long, D., \& Beers, M. C. (1998). Successful knowledge management projects. Sloan Management Review , 43-57.

- Ford/GM/Chrysler. (1995). Advanced Product Quality Planning and Control Plan. Essex: Carwin Continous.

- Galliers, R. D., \& Newell, S. (2003). Back to the future: from knowledge management. ISeB , 513. 
- Kiku, J., \& Lori, L. (2009). From Tacit Knowledge to Organizational Knowledge for Successful KM. In W. R. King, Knowledge Management and Organizational Learning (pp. 27-39). New York: Springer.

- King, W. (2005). Communications and information processing as a critical success factor in the effective knowledge organization. International Journal of Business Information Systems 10(5) , 31-52.

- King, W. R. (2009). Knowledge Management and Organizational Learning. In W. R. King, Knowledge Management and Organizational Learning (pp. 3-13). New York: Springer.

- Morris, M. (2012). Retrieved 7 7, 2013, from Advanced Product Quality Planning: static.squarespace.com

- Nonaka, I., \& Takeguci, H. (1995). The knowledge-creating company. Oxford: Oxford University Press.

- O'Dell, C., \& Hubert, C. (2011). The New Edge in Knowledge. New Jersey: John Wiley \& Sons.

- Oxford Dictionary. (n.d.). Retrieved Februarie 7, 2013, from Oxford Dictionary: http://oxforddictionaries.com/

- Polanyi, M. (1967). The tacit dimension. London: Routledge and Kegan Paul .

- Ruggles, R. (1999). The state of the notion: Knowledge management in practice. The Knowledge Management Yearbook 1999-2000, 295.

- Wilson, T. (2002). The nonsense of knowledge management. Information Research, 8(1) , 144183. 